\title{
Sport-specific association between exercise loading and the density, geometry, and microstructure of weight-bearing bone in young adult men
}

\author{
M. Nilsson • C. Ohlsson • D. Mellström • M. Lorentzon
}

Received: 17 April 2012 /Accepted: 5 September 2012 /Published online: 26 September 2012

(C) The Author(s) 2012. This article is published with open access at Springerlink.com

\begin{abstract}
Summary In this population-based study of 24-year-old men, we have investigated the association between sportspecific exercise loading and different bone parameters. We reveal that the association between exercise loading and bone parameters is sport-specific, indicating that nonspecific resistance exercise does not impact bone density, geometry, or microstructure in young men.

Introduction In this cross-sectional study, the association between nonspecific resistive exercise and areal and volumetric bone density, bone geometry, or bone microstructure was investigated in young adult men.

Methods A total of 184 male athletes, $24.0 \pm 0.6$ years of age (mean $\pm \mathrm{SD})$, representing nonspecific resistive exercise and soccer (proportion of recreational athletes, 93.4 and $7.7 \%$, respectively), and 177 nonathletic age-matched controls were measured with dual-energy X-ray absorptiometry. Radius and tibia were measured by peripheral quantitative computed tomography (pQCT) at the diaphysis and by three-dimensional $\mathrm{pQCT}$ at the metaphysis.
\end{abstract}

M. Nilsson · C. Ohlsson · D. Mellström · M. Lorentzon

Centre for Bone and Arthritis Research at the Sahlgrenska

Academy, Department of Internal Medicine,

University of Gothenburg,

Gothenburg, Sweden

C. Ohlsson

e-mail: claes.ohlsson@medic.gu.se

D. Mellström

e-mail: dan.mellstrom@vgregion.se

M. Lorentzon

e-mail: mattias.lorentzon@medic.gu.se

M. Nilsson ( $\square)$

Centre for Bone and Arthritis Research, Institute of Medicine,

Sahlgrenska Academy, Sahlgrenska University Hospital,

Vita Stråket 11,

41345 Gothenburg, Sweden

e-mail: martin.nilsson@medic.gu.se
Results Men in the nonspecific resistive exercise group had higher grip strength $(9.1 \%$ or $0.4 \mathrm{SD})$ and higher lean mass $(5.6 \%$ or $0.5 \mathrm{SD})$ than those in the nonathletic $\operatorname{group}(p<$ 0.01 and $p<0.001$, respectively). However, men who participated in nonspecific resistive exercise did not have higher bone density or a more favorable bone microstructure or geometry than their nonathletic referents. In contrast, men playing soccer had higher areal bone mineral density (aBMD) at the femoral neck (19.5\% or $1.2 \mathrm{SD})$ and lumbar spine $(12.6 \%$ or $1.0 \mathrm{SD})$, as well as larger cortical crosssectional area (16.4\% or $1.1 \mathrm{SD})$ and higher trabecular bone volume fraction $(14.5 \%$ or $0.9 \mathrm{SD})$, as a result of increased trabecular number $(8.7 \%$ or $0.6 \mathrm{SD})$ and thickness $(5.7 \%$ or 0.4 $\mathrm{SD})$ at the tibia than men in the nonathletic $\operatorname{group}(p<0.001)$. Conclusions Weight-bearing exercise with impacts from varying directions (playing soccer) is associated with aBMD and volumetric BMD, cortical bone geometry, as well as trabecular microstructure of weight-bearing bone. Nonspecific recreational resistance exercise does not appear to be a strong determinant of bone density, geometry, or microstructure in young adult men.

Keywords Bone geometry $\cdot$ Bone microstructure $\cdot$ Bone mineral density $\cdot$ Exercise $\cdot$ Men

\section{Introduction}

Even though variance in bone mass is mostly genetically determined [1], it is well known that bones adapt to a specific mechanical loading to which they are habitually exposed [2]. Physical exercise has been suggested as an intervention strategy to promote optimal bone gain and bone strength during youth [3] and to reduce the rate of bone loss later in life [4]. Weight-bearing loading has also been found to be more effective than nonweight-bearing activities such 
as swimming and bicycling in the enhancement of bone mass [5-9]. Bone tissue responds to dynamic rather than static loading [10], and several studies have suggested that the type of physical activity and the accompanying dynamic activity are of particular importance [11-15]. The maximum effect is believed to be achieved by weight-bearing physical activity including jumping actions, explosive actions (such as turning and sprinting), and fairly few repetitions rather than endurance or nonweight-bearing activities [5, 8, 16-18].

Peak bone mass is believed to be achieved before the end of the third decade in life, depending on bone site, and low peak bone mass has been considered as a risk factor for developing osteoporosis later in life $[1,19,20]$. Higher peak bone mass attained through weight-bearing exercise may also contribute to a larger bone size and higher bone strength in older men [21, 22].

Both skeletal muscle mass and lean body mass are correlated with bone mineral density (BMD) at different skeletal sites [23, 24]. Exercise by resistance training is common and increasingly popular in the younger population [25] and is recommended to promote and maintain health and physical independence in all healthy adults, if the exercise is performed for a minimum of 2 days each week [26]. Resistance training can offer several health benefits, such as improved cardiovascular function and motor skill performance, and it can reduce the risk of developing some chronic diseases later in life [25]. Exercise programs that combine jumping and turning and sprinting actions with resistance training appear effective in augmenting BMD at the hip and spine in premenopausal women [27], but the effect of isolated resistance exercise on bone mass has been less well studied. Based on multiple but small randomized controlled trials, it has been suggested that resistance training can have an osteogenic effect [28]. In contrast, two studies have found that power-lifting female athletes using high-magnitude muscle forces show no significant bone gain compared to nonathletic female subjects $[18,29]$. "Resistance training" is defined as a specialized method of physical conditioning designed to enhance health, fitness, and sports performance, using different movement velocities and a variety of training modalities, e.g., weight machines, free weights, elastic bands, and medicine balls. Resistance training encompasses a broader range of training modalities and a wider variety of training goals than the often synonymously used "strength and weight training" [30]. According to the literature, weight-bearing exercise with impact from varying directions, e.g., playing soccer, has beneficial effects on bone mass accrual [28]. Therefore, we hypothesized that it would be interesting to compare both resistance training and soccer playing with nonathletic subjects from the same population.

In the large majority of previous studies that have investigated the association between exercise and bone mass, bone properties have been measured using dual-energy X-ray absorptiometry (DXA). Since the DXA technique cannot distinguish whether changes in BMD are due to changes in bone volumetric BMD (vBMD) or in bone geometrical parameters [31], data regarding the role of physical activity on bone structural parameters is scarce.

The aim of this cross-sectional study was to investigate whether resistance training is associated with areal and volumetric bone density, bone geometry, or bone microstructure in young adult men.

\section{Materials and methods}

\section{Subjects}

The study subjects were a subsample of the population-based Gothenburg Osteoporosis and Obesity Determinants (GOOD) study initiated with the aim to determine both environmental and genetic factors involved in the regulation of bone mass $[32,33]$. Out of the original 833 subjects, 361 men, between 22.8 and 25.7 years old $(24.1 \pm 0.6$ years $)$, were included in the present cross-sectional study. To be included in the present study, subjects had to actively exercise with resistance training $(n=106)$ or soccer $(n=78)$ as their main sporting activity. Subjects with no history of exercise were used as nonathletic referents $(n=177)$. The original GOOD cohort was found to be representative of the general young male population in Gothenburg [33], and the cohort at the follow-up visit was found to be representative of the initial population [32]. The study was approved by the Regional Ethical Review Board at the University of Gothenburg. Written and oral informed consent was obtained from all study participants.

\section{Present physical activity}

A standardized self-administered questionnaire, based on a validated physical activity questionnaire to measure the effect of mechanical strain on bone mass [34] with amendments, was used to collect information about patterns of present physical activity in sports and exercise. Information on the type of physical activity as well as duration (in hours per week) and number of years spent on all present physical activities in relation to sports and exercise was collected. Subjects were divided into two groups according to their main present activity: resistance training $(n=106)$ or soccer $(n=78)$. Seven subjects $(6.6 \%)$ in the resistance training group and 72 subjects $(92.3 \%)$ in the soccer-playing group classified themselves as being competitive athletes. Subjects who had never been active in sports, with neither competitive nor recreational purpose, were used as nonathletic referents $(n=177)$. We did not record information regarding kinds of resistive exercises, loading levels, number of sets, or number of repetitions performed in the resistance training group. Information on occupational physical loading (in metabolic equivalent of task), sedentary behavior (total time (in hours per week) sitting 
down, e.g., watching TV or using a computer), and type of daily transportation (walking, bicycling, or passive transportation, e.g., public transportation, driving a car or motorcycle) was also collected by questionnaire.

Anthropometrics, calcium intake, and smoking status

Height and weight were measured using standardized equipment. The coefficient of variation $(\mathrm{CV})$ values were $<1 \%$ for these measurements. A standardized self-administered questionnaire was used to collect information about calcium and smoking (yes/no). Calcium intake (in milligrams per day) was estimated from dairy product intake.

\section{Grip strength}

Grip strength was assessed using a Jamar hydraulic hand dynamometer (5030J1, Jackson, MI, USA) with adjustable handgrip. The subjects sat in a standard chair with both the forearm and dynamometer resting on a table. The subjects were asked to hold the dynamometer firmly and in an upright position, and then squeeze the handle as hard as they could. Three trials of each hand were performed. The results were recorded in kilograms of force, and the mean value of the three results for the nondominant hand was used in this study.

\section{Areal BMD and body composition}

Areal bone mineral density (aBMD, in grams per square centimeter) of the total body, lumbar spine (L1-L4), total hip, femoral neck, and nondominant radius as well as total body lean and fat mass were assessed using a DXA device (the Lunar Prodigy DXA, GE Lunar, Madison, WI, USA). The CV for the aBMD measurements ranged from 0.5 to $3 \%$, depending on application. Two subjects could not undergo total body, lumbar spine, or hip scan due to the weight limits of the Lunar Prodigy DXA [32]. The same device, software, and operator were used throughout the study.

\section{Cortical bone geometry and volumetric BMD}

A peripheral quantitative computed tomography (pQCT) device (XCT-2000; Stratec Medizintechnik, Pforzheim, Germany) was used to scan the distal leg (tibia) and the distal arm (radius) of the nondominant leg and arm, respectively. A 2-mm-thick single tomographic slice was scanned with a voxel size of $0.50 \mathrm{~mm}$. The cortical cross-sectional area (CSA, in square millimeter), endosteal and periosteal circumference (EC and PC, respectively, in millimeters), cortical thickness (in millimeters), and cortical volumetric density (in milligrams per cubic centimeter) were measured using a scan through the diaphysis (at $25 \%$ of the bone length in the proximal direction of the distal end of the bone) of the radius and tibia. Tibia length was measured from the medial malleolus to the medial condyle of the tibia, and the length of the forearm was defined as the distance from the olecranon to the ulna styloid process. The CVs were $<1 \%$ for all pQCT measurements [32]. The same device, software, and operator were used throughout the study. A threshold-driven analysis was used $\left(710 \mathrm{mg} / \mathrm{cm}^{3}\right)$.

Bone microarchitectural measurement

A high-resolution three-dimensional (3D) pQCT device (XtremeCT, Scanco Medical AG, Bassersdorf, Switzerland) was used to scan the ultradistal tibia and the ultradistal radius of the nondominant leg and arm, respectively, in 361 of the original 363 subjects. The right arm and leg of right-handed men was defined as their dominant side, while the left arm and leg of left-handed men was defined as their dominant side. Anatomically formed carbon fiber shells, designed for each type of limb (Scanco Medical AG, Bassersdorf, Switzerland), were used to immobilize the subject's arm or leg during the scan. The measurements of the volume of interest in the ultradistal tibia and radius, $1 \mathrm{~cm}$ in the proximal direction and the whole cross-section in transversal direction, were carried out according to a standardized protocol previously described $[35,36]$. Briefly, a reference line was manually placed at the center of the endplate of the distal tibia and distal radius. The first CT slice started 22.5 and $9.5 \mathrm{~mm}$ proximal to the reference line for the tibia and radius, respectively. One hundred ten parallel CT slices, with a nominal isotropic resolution (voxel size) of $82 \mu \mathrm{m}$, were obtained at each skeletal site, delivering a 3D representation of approximately sections of thickness $9 \mathrm{~mm}$ of both the tibia and radius in the proximal direction. At each skeletal site, the entire volume of interest was automatically separated into a cortical and a trabecular region. From this separation and using previously described methods to process the data [36], we obtained volumetric cortical (D.Cort, in milligrams per cubic centimeter) and trabecular bone density (D.Trab, in milligrams per cubic centimeter), trabecular bone volume fraction (BV/TV, in percent), trabecular number (Tb.N, per millimeter), trabecular separation (Tb.Sp, in millimeters), and trabecular thickness (Tb.Th, in micrometers). The data for D.Trab and BV/TV has a near 1:1 relationship.

The quality of the measurements of the tibia and radius were assessed by a five-grade scale, recommended by the manufacturer (Scanco Medical AG, Bassersdorf, Switzerland), where 1 had the highest quality, 2 to 3 had acceptable quality (included in the analyses), and 4 to 5 had unacceptable quality (excluded from the analyses) due to artifacts caused by inadequate limb fixation. A total of 1 measurement of the leg and 42 measurements of the arm were considered to have unacceptable quality (grade 4 or 5), leaving 360 subjects for further analysis of the tibia and 319 subjects for further analysis of the radius. The $\mathrm{CVs}$ for 
the bone measurements used were obtained by three repeated measurements according to the standardized protocol on two subjects. The CVs ranged from 0.2 to $1.6 \%$ for the tibia and from 0.5 to $3.7 \%$ for the radius [37]. The same device, software, and operator were used throughout the study.

\section{Statistical analysis}

All data were analyzed using SPSS software, version 17.0 for Windows. Differences in characteristics and bone parameters between subjects divided according to present sport activity were calculated using two-sample $t$ test analysis of variance (ANOVA) or analysis of covariance (ANCOVA), followed by Tukey's post hoc test for continuous variables and by chi-square for categorical variables. In all analyses, a $p$ value of $<0.05$ was considered to be statistically significant. With $80 \%$ statistical power, $5 \%$ alpha error level, and $n=78$ (soccer) or $n=106$ (resistance exercise), the study was able to detect an effect size of $d=$ 0.32 or $d=0.27$, respectively, for aBMD at the femoral neck.

\section{Results}

\section{Characteristics}

Table 1 shows the subject characteristics and training history of the cohort according to sport and exercise activity. The mean duration of exercise exceeded $4 \mathrm{~h} /$ week and the mean history of activity exceeded 5 years in both groups of athletes. There were no significant differences in height, weight, calcium intake, occupational physical load, sedentary behavior, or daily transportation between the different groups. Subjects in the soccerplaying group were slightly younger than their nonathletic counterparts. As could be expected, the athletes had lower fat mass and fat percentage, had higher lean mass, and were less frequently smokers than subjects in the nonathletic group (Table 1). Men in the resistance training group had significantly higher grip strength $(9.1 \%$ or $0.4 \mathrm{SD})$ than those in the nonathletic group (Table 1; Fig. 1). When adjusting for height and weight, all associations between sport-specific exercise loading and grip strength or lean mass remained (Table 1). In addition, men in the soccer-playing group had significantly higher adjusted lean mass than men in the resistance training group (Table 1).

Association between type of exercise loading and bone parameters

Resistance training men did not have significantly higher aBMD or a more favorable bone microstructure or geometry than their nonathletic referents (Table 2; Figs. 2 and 3). In contrast, men in the soccer playing group had higher aBMD of the femoral neck $(19.5 \%$ or $1.2 \mathrm{SD})$ and lumbar spine (12.6\% or $1.0 \mathrm{SD})$, larger cortical bone size at the tibia (CSA and PC, $16.4 \%$ or 1.1 SD and $5.1 \%$ or $0.8 \mathrm{SD}$, respectively), and higher trabecular bone volume fraction (BV/TV, $14.5 \%$ or $0.9 \mathrm{SD})$ as a result of increased trabecular number (Tb.N, $8.7 \%$ or $0.6 \mathrm{SD}$ ) and thickness (Tb.Th, $5.7 \%$ or $0.4 \mathrm{SD}$ ) at the tibia than men in the nonathletic group (Figs. 2 and 3; Table 2). Similar but weaker associations were found in corresponding bone sites at the radius (Table 2). Men in the soccer-playing group had also higher aBMD of the femoral neck ( $18.0 \%$ or $1.1 \mathrm{SD})$ and lumbar spine $(10.1 \%$ or $0.8 \mathrm{SD}$ ), larger cortical bone size at the tibia (CSA and PC, $12.9 \%$ or $0.9 \mathrm{SD}$ and $3.7 \%$ or $0.6 \mathrm{SD}$, respectively), and higher trabecular bone volume fraction (BV/TV, $15.5 \%$ or $1.0 \mathrm{SD}$ ) and trabecular number (Tb.N, $10.2 \%$ or $0.7 \mathrm{SD}$ ) at the tibia than men in the resistance training group (Figs. 2 and 3; Table 2). When we adjusted for height and weight, the associations between sport-specific exercise loading and bone parameters remained and some additional associations emerged (Table 3). Thus, men in the resistance training group had significantly higher PC, adjusted for height and weight, at the radius than men in the nonathletic group (Table 3). In addition, soccer players had thicker height-adjusted and weight-adjusted trabeculae (Tb.Th) at the tibia than men in the resistance training group (Table 3). When we adjusted for smoking, all associations between sport-specific exercise loading and bone parameters remained with two exceptions, i.e., soccer players no longer had a significantly higher trabecular BV/TV or trabecular thickness at the radius than their nonathletic referents (Table 3).

\section{Discussion}

We have previously reported, in a cross-sectional analysis in the GOOD study, that young men who participate in more than $4 \mathrm{~h}$ of physical activity per week have higher aBMD and greater cortical bone size than sedentary men of the same age [13]. In the present study, we found that men with soccer as their main sport had higher aBMD and more favorable bone microstructure and geometry than men with resistance training as their main sport. Thus, no apparent advantage in aBMD, bone size, or microstructure was seen in resistance training men despite the fact that the mean duration of exercise exceeded $4 \mathrm{~h} /$ week and the mean history of activity exceeded 5 years in these men. In contrast, we found that men in the resistance training group had $9.5 \%$ higher grip strength and $5.5 \%$ more lean mass, while men in the soccer-playing group only had more lean mass $(9.1 \%)$ than those in the nonathletic group. Hence, resistance training may be effective in increasing muscle mass and strength, but may not substantially improve bone strength. We have previously reported that boys who began their physical activity before puberty, as in the soccer-playing group, had higher adult aBMD and cortical bone size than boys who started training later [13]. However, we have recently also 
Table 1 Characteristics of the cohort according to sport activity

\begin{tabular}{|c|c|c|c|c|c|}
\hline & \multirow[t]{2}{*}{ Non-athletic referents } & \multicolumn{2}{|l|}{ Type of exercise } & \multirow[t]{2}{*}{ ANOVA $p$} & \multirow[t]{2}{*}{ ANCOVA $p$} \\
\hline & & Resistance training & Soccer & & \\
\hline Number of subjects & 177 & 106 & 78 & & \\
\hline Age (years) & $24.2 \pm 0.6$ & $24.0 \pm 0.7$ & $23.9 \pm 0.6 \mathrm{a}$ & 0.031 & \\
\hline Height $(\mathrm{cm})$ & $181.9 \pm 6.8$ & $182.4 \pm 6.8$ & $180.6 \pm 6.6$ & 0.819 & \\
\hline Weight (kg) & $79.2 \pm 15.9$ & $78.8 \pm 11.1$ & $80.2 \pm 10.7$ & 0.772 & \\
\hline Calcium intake (mg/day) & $793 \pm 527$ & $836 \pm 579$ & $781 \pm 414$ & 0.733 & \\
\hline Lean mass $(\mathrm{kg})^{\mathrm{a}}$ & $56.3 \pm 6.1$ & $59.4 \pm 5.8 \mathbf{A}$ & $61.4 \pm 6.3 \mathbf{A}$ & $<0.001$ & \\
\hline Adjusted lean mass $(\mathrm{kg})^{\mathrm{a}}$ & $56.5 \pm 3.7$ & $59.3 \pm 4.2 \mathbf{A}$ & $61.1 \pm 3.9 \mathbf{A}, \mathrm{B}$ & & $<0.001$ \\
\hline Fat mass $(\mathrm{kg})^{\mathrm{a}}$ & $19.8 \pm 10.7$ & $16.8 \pm 8.1 \mathrm{a}$ & $15.4 \pm 6.1 \mathrm{~A}$ & 0.001 & \\
\hline Fat percent ${ }^{\mathrm{a}}$ & $23.7 \pm 8.9$ & $20.5 \pm 7.2 \mathrm{~A}$ & $18.8 \pm 6.0 \mathbf{A}$ & $<0.001$ & \\
\hline Grip strength $(\mathrm{kg})^{\mathrm{b}}$ & $48.6 \pm 10.5$ & $53.0 \pm 9.2 \mathrm{~A}$ & $51.1 \pm 9.9$ & 0.002 & \\
\hline Adjusted grip strength $(\mathrm{kg})^{\mathrm{b}}$ & $48.6 \pm 10.3$ & $53.0 \pm 9.0 \mathrm{~A}$ & $50.9 \pm 9.4$ & & 0.001 \\
\hline Smoking (\%) & 16.9 & $5.6 \mathrm{~A}$ & $1.3 \mathrm{~A}$ & & \\
\hline Occupational physical loading (MET) & $3.1 \pm 2.9$ & $3.5 \pm 2.9$ & $3.5 \pm 2.9$ & 0.434 & \\
\hline Sedentary behavior (h/week) & $25.5 \pm 17.6$ & $25.1 \pm 22.7$ & $22.2 \pm 18.9$ & 0.455 & \\
\hline \multicolumn{6}{|l|}{ Daily transportation } \\
\hline Walking (\%) & 15.3 & 10.2 & 10.3 & & \\
\hline Bicycling (\%) & 11.3 & 12.0 & 9.0 & & \\
\hline Passive transportation $(\%)$ & 73.4 & 77.8 & 80.8 & & \\
\hline \multicolumn{6}{|l|}{ Specific sport } \\
\hline Duration of training ( $\mathrm{h} /$ week) & - & $3.0 \pm 2.3$ & $3.8 \pm 2.2 b$ & & \\
\hline History of training (year) & - & $5.1 \pm 3.4$ & $14.9 \pm 5.6 \mathbf{B}$ & & \\
\hline \multicolumn{6}{|l|}{ All sports } \\
\hline Duration of training ( $\mathrm{h} /$ week) & - & $4.1 \pm 2.7$ & $5.7 \pm 2.8 \mathbf{B}$ & & \\
\hline History of training (year) & - & $5.6 \pm 4.1$ & $15.3 \pm 5.1 \mathbf{B}$ & & \\
\hline
\end{tabular}

Values are given as mean \pm SD. Differences between the groups tested by $t$ test, ANOVA, or ANCOVA (with height and weight as covariates) followed by Tukey's post hoc test for continuous variables and by chi-square for categorical variables. $p$ values for vs. nonathletic (indicated by A) and vs. resistance training (indicated by B). Capital and lowercase letters represent $p<0.01$ and $p<0.05$, respectively. Capital bold type letters represent $p<0.001(n=361)$

MET metabolic equivalent of task, Sedentary behavior total time (h/week) sitting down, e.g., watching TV or using a computer

${ }^{\mathrm{a}} n=359$

${ }^{\mathrm{b}} n=353$

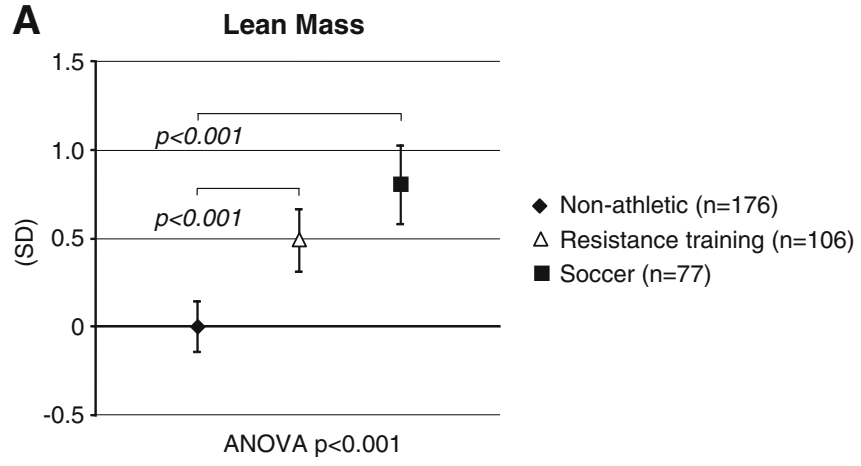

Fig. 1 a, b Sport-specific association between exercise loading and grip strength or lean mass. One-way ANOVA followed by Tukey's post hoc test was used for evaluating differences between the

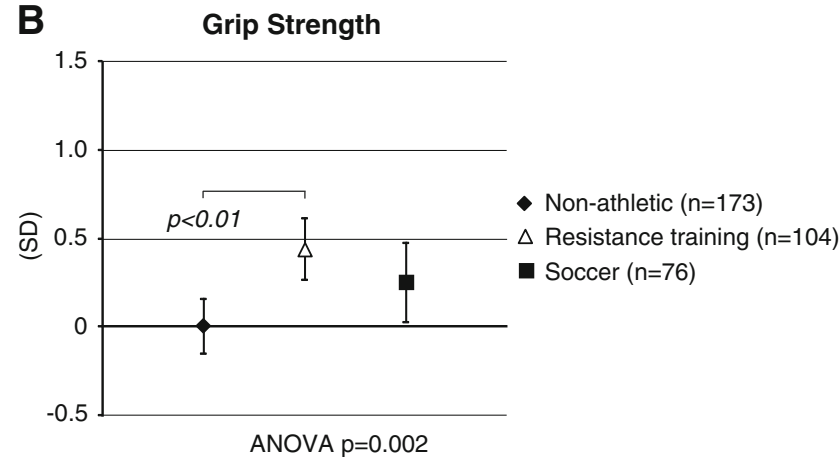

nonathletic, resistance training, and soccer-playing groups of young adult men. Values are given as mean difference $(\mathrm{SD} \pm 95 \% \mathrm{CI}) \mathrm{com}-$ pared to the mean of the nonathletic group, represented by the 0 line 
Table 2 Sport-specific association between exercise loading and density, geometry, and microstructure of weight-bearing bone in young adult men

\begin{tabular}{|c|c|c|c|c|}
\hline & \multirow[t]{2}{*}{ Non-athletic referents } & \multicolumn{2}{|l|}{ Type of exercise } & \multirow[t]{2}{*}{ ANOVA $p$} \\
\hline & & Resistance training & Soccer & \\
\hline Number of subjects & 177 & 106 & 78 & \\
\hline \multicolumn{5}{|l|}{ Areal bone mineral density } \\
\hline Total body $\left(\mathrm{g} / \mathrm{cm}^{2}\right)^{\mathrm{a}}$ & $1.25 \pm 0.09$ & $1.27 \pm 0.09$ & $1.36 \pm 0.09 \mathbf{A}, \mathbf{B}$ & $<0.001$ \\
\hline Lumbar spine $\left(\mathrm{g} / \mathrm{cm}^{2}\right)^{\mathrm{a}}$ & $1.21 \pm 0.13$ & $1.23 \pm 0.14$ & $1.36 \pm 0.15 \mathbf{A}, \mathbf{B}$ & $<0.001$ \\
\hline Femoral neck $\left(\mathrm{g} / \mathrm{cm}^{2}\right)^{\mathrm{a}}$ & $1.06 \pm 0.14$ & $1.07 \pm 0.15$ & $1.26 \pm 0.17 \mathbf{A}, \mathbf{B}$ & $<0.001$ \\
\hline Total hip $\left(\mathrm{g} / \mathrm{cm}^{2}\right)^{\mathrm{a}}$ & $1.08 \pm 0.14$ & $1.09 \pm 0.16$ & $1.29 \pm 0.17 \mathbf{A}, \mathbf{B}$ & $<0.001$ \\
\hline Radius nondominant $\left(\mathrm{g} / \mathrm{cm}^{2}\right)$ & $0.62 \pm 0.06$ & $0.63 \pm 0.05$ & $0.63 \pm 0.05$ & 0.126 \\
\hline \multicolumn{5}{|l|}{ Tibial diaphysis } \\
\hline Cortical cross-sectional area $\left(\mathrm{mm}^{2}\right)$ & $266 \pm 33$ & $275 \pm 37$ & $310 \pm 34 \mathbf{A}, \mathbf{B}$ & $<0.001$ \\
\hline Cortical periosteal circumference (mm) & $73.1 \pm 4.8$ & $74.0 \pm 4.8$ & $76.8 \pm 4.3 \mathbf{A}, \mathbf{B}$ & $<0.001$ \\
\hline Cortical thickness (mm) & $4.54 \pm 0.47$ & $4.63 \pm 0.57$ & $5.13 \pm 0.56 \mathbf{A}, \mathbf{B}$ & $<0.001$ \\
\hline Cortical endosteal circumference (mm) & $44.5 \pm 5.2$ & $44.9 \pm 5.3$ & $44.5 \pm 5.5$ & 0.818 \\
\hline Cortical volumetric density $\left(\mathrm{mg} / \mathrm{cm}^{3}\right)$ & $1,169 \pm 17$ & $1,164 \pm 19$ & $1,155 \pm 21 \mathbf{A}, \mathrm{B}$ & $<0.001$ \\
\hline \multicolumn{5}{|l|}{ Radial diaphysis } \\
\hline Cortical cross-sectional area $\left(\mathrm{mm}^{2}\right)$ & $95.6 \pm 12.9$ & $98.9 \pm 11.9$ & $100.7 \pm 11.0 \mathrm{~A}$ & 0.004 \\
\hline Cortical periosteal circumference (mm) & $41.4 \pm 3.1$ & $42.2 \pm 2.9$ & $42.7 \pm 2.8 \mathrm{~A}$ & 0.002 \\
\hline Cortical volumetric density $\left(\mathrm{mg} / \mathrm{cm}^{3}\right)$ & $1,194 \pm 16$ & $1,188 \pm 17 \mathrm{a}$ & $1,189 \pm 17$ & 0.007 \\
\hline \multicolumn{5}{|l|}{ Tibial metaphysis } \\
\hline Trabecular bone volume fraction $(\%)^{\mathrm{b}}$ & $17.6 \pm 2.6$ & $17.5 \pm 2.6$ & $20.3 \pm 2.3 \mathbf{A}, \mathbf{B}$ & $<0.001$ \\
\hline Trabecular number $\left(\mathrm{mm}^{-1}\right)^{\mathrm{b}}$ & $2.07 \pm 0.28$ & $2.04 \pm 0.28$ & $2.25 \pm 0.27 \mathbf{A}, \mathbf{B}$ & $<0.001$ \\
\hline Trabecular volumetric density $\left(\mathrm{mg} / \mathrm{cm}^{3}\right)^{\mathrm{b}}$ & $211.6 \pm 31.1$ & $210.5 \pm 31.5$ & $243.2 \pm 28.3 \mathbf{A}, \mathbf{B}$ & $<0.001$ \\
\hline Trabecular separation $(\mathrm{mm})^{\mathrm{b}}$ & $0.41 \pm 0.07$ & $0.41 \pm 0.07$ & $0.36 \pm 0.05 \mathbf{A}, \mathbf{B}$ & $<0.001$ \\
\hline Trabecular thickness $(\mu \mathrm{m})^{\mathrm{b}}$ & $85.9 \pm 11.0$ & $86.8 \pm 12.2$ & $90.8 \pm 11.0 \mathrm{~A}$ & 0.007 \\
\hline Cortical volumetric density $\left(\mathrm{mg} / \mathrm{cm}^{3}\right)^{\mathrm{b}}$ & $874 \pm 35$ & $867 \pm 33$ & $872 \pm 30$ & 0.245 \\
\hline \multicolumn{5}{|l|}{ Radial metaphysis } \\
\hline Trabecular bone volume fraction $(\%)^{\mathrm{c}}$ & $16.3 \pm 2.9$ & $16.5 \pm 2.8$ & $17.3 \pm 2.7 \mathrm{a}$ & 0.035 \\
\hline Trabecular number $\left(\mathrm{mm}^{-1}\right)^{\mathrm{c}}$ & $2.1 \pm 0.3$ & $2.1 \pm 0.2$ & $2.1 \pm 0.3$ & 0.675 \\
\hline Trabecular separation $(\mathrm{mm})^{\mathrm{c}}$ & $0.40 \pm 0.06$ & $0.41 \pm 0.06$ & $0.40 \pm 0.06$ & 0.593 \\
\hline Trabecular thickness $(\mu \mathrm{m})^{\mathrm{c}}$ & $77.5 \pm 12.4$ & $79.4 \pm 12.1$ & $82.5 \pm 12.9 \mathrm{a}$ & 0.021 \\
\hline Cortical volumetric density $\left(\mathrm{mg} / \mathrm{cm}^{3}\right)^{\mathrm{c}}$ & $851 \pm 43$ & $840 \pm 40$ & $852 \pm 39$ & 0.064 \\
\hline
\end{tabular}

Mean \pm SD of bone parameters are presented. Differences between groups tested by ANOVA followed by Tukey's post hoc test were performed $(n=$ 361). $p$ values for vs. nonathletic (indicated by A) and vs. resistance training (indicated by B). Capital and capital bold type letters represent $p<0.01$ and $p<0.001$, respectively. Lowercase letters represent $p<0.05$

${ }^{\mathrm{a}} n=359$

${ }^{\mathrm{b}} n=358$

${ }^{\mathrm{c}} n=317$

reported, in a longitudinal study, that men who start to exercise after the age of 18 years, as in the resistance training group, can increase their adult aBMD, vBMD, and cortical bone size [38].

Muscle forces and gravitational loading can affect bone mass [39], and both the magnitude and intensity of the loading seem to be important for the osteogenic effect. We have previously reported that gravitational loading is associated with trabecular microstructure and cortical bone at the distal tibia in young adult men [37]. When playing soccer, the skeleton is exposed to irregular dynamic loading from different directions. In agreement with previous studies in both animals and humans, we found that this type of boneloading activity was related to higher BMD and favorable bone geometry $[3,28]$. In the present study, we analyzed a subgroup exposed to low gravitational loading via exercise but with high muscle force. A previous study demonstrated that muscle strength seems to have a positive effect on aBMD of the insertion site of the quadriceps muscle in adolescent boys [40]. Cohort studies have demonstrated that 


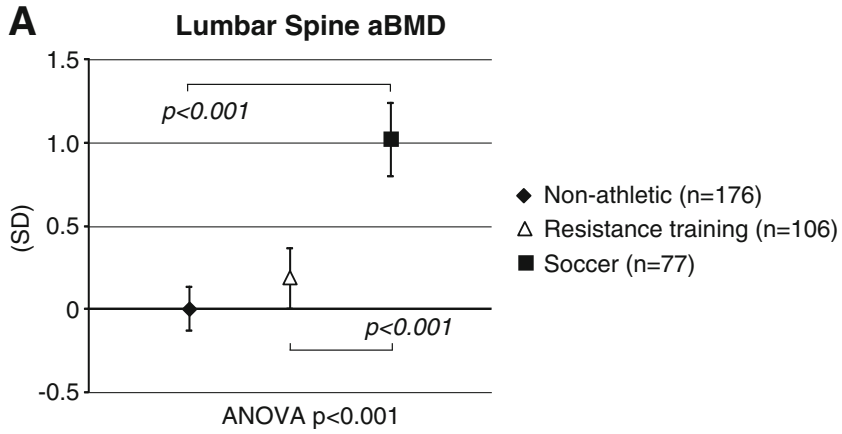

Fig. 2 a, b Sport-specific association between exercise loading and aBMD. One-way ANOVA followed by Tukey's post hoc test was used for evaluating differences between the nonathletic, resistance training,

physical training before and during puberty are associated with increased bone acquisition in children and young adults $[13,41,42]$. However, the skeleton of older persons seems to be less adaptive to physical activity-induced mechanical loading applied to it $[3,43]$.

According to previous studies, power-lifting female athletes show no significant bone gain compared to nonathletic female subjects $[18,29]$. In contrast, other studies have shown significantly higher aBMD in elite male weightlifters compared to age-matched controls of both nonathletic [44, 45] and recreational low-intensity resistance training young

\section{A Tibial Cortical Cross Sectional Area}

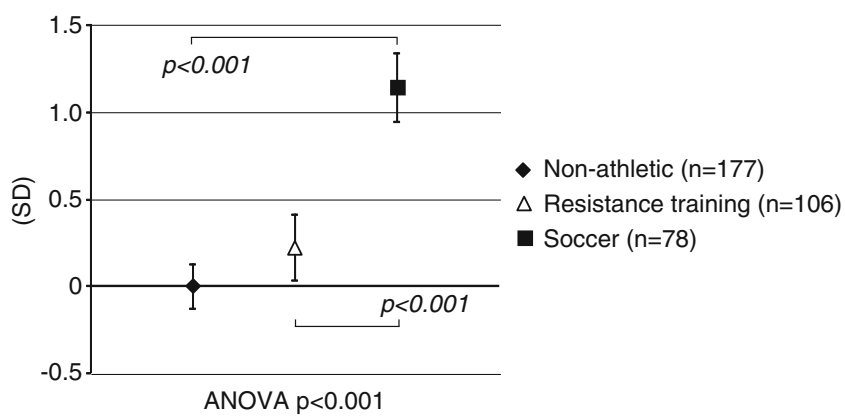

C Tibial Trabecular Bone Volume Fraction

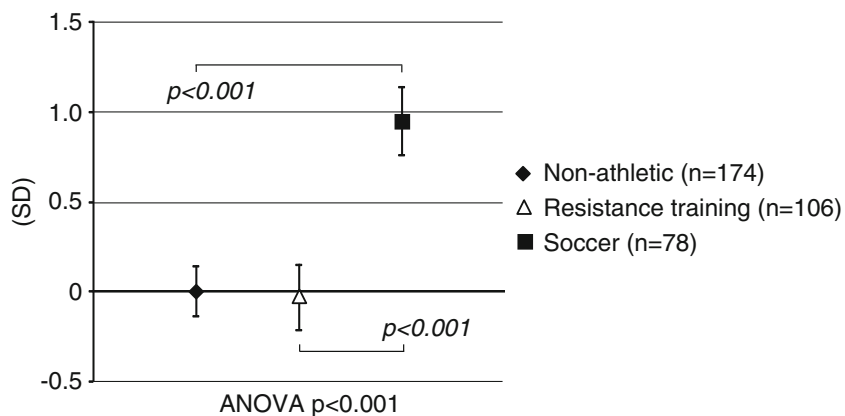

Fig. 3 a-d Sport-specific association between exercise loading and volumetric density, geometry, or microstructure in weight-bearing bone. One-way ANOVA followed by Tukey's post hoc test was used for evaluating differences between the nonathletic, resistance training,

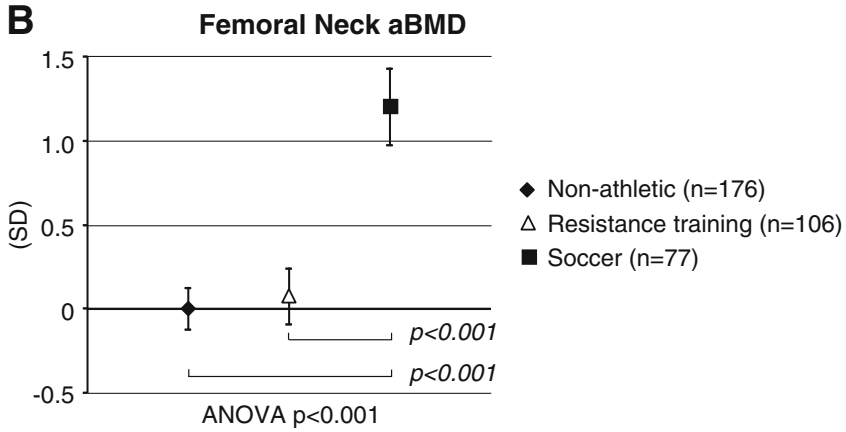

and soccer-playing groups of young adult men. Values are given as mean difference $(\mathrm{SD} \pm 95 \% \mathrm{CI}$ ) compared to the mean of the nonathletic group, represented by the 0 line

men [46]. However, the terms "weightlifting" and "power lifting" refer to competitive sports that involve exercise with heavy loads and attempts to lift maximal amounts of weight, while the sport of "bodybuilding" has the goal to maximize muscle size, symmetry, and definition. These terms should, therefore, be distinguished from the term "resistance training" with the design to enhance health, fitness, and sports performance [30]. Thus, habitual bodybuilding and resistance training may not be expected to be beneficial for bone health, whereas exercise for competitive weightlifting and power lifting to obtain maximal power might be beneficial.
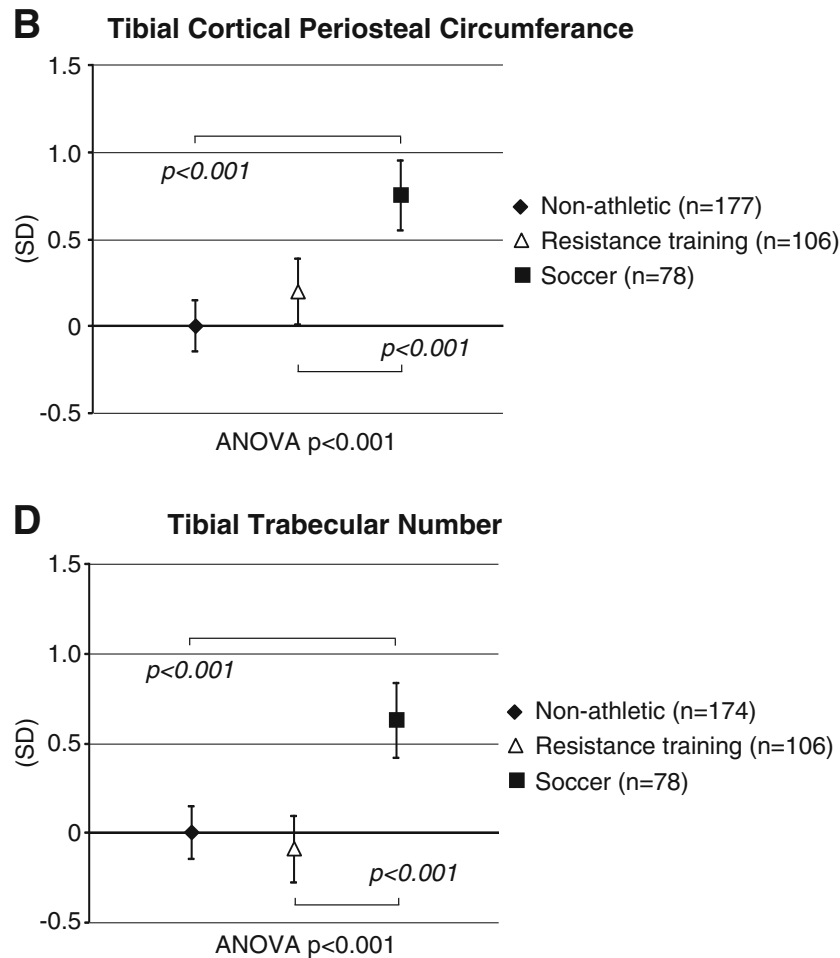

and soccer-playing groups of young adult men. Values are given as mean difference $(\mathrm{SD} \pm 95 \% \mathrm{CI})$ compared to the mean of the nonathletic group, represented by the 0 line 
Table 3 Adjusted sport-specific association between exercise loading and density, geometry, and microstructure of weight-bearing bone in young adult men

\begin{tabular}{|c|c|c|c|c|c|}
\hline & \multirow[t]{2}{*}{ Non-athletic referents } & \multicolumn{2}{|l|}{ Type of exercise } & \multirow[t]{2}{*}{ ANCOVA1 $p$} & \multirow[t]{2}{*}{ ANCOVA $2 p$} \\
\hline & & Resistance training & Soccer & & \\
\hline Number of subjects & 177 & 106 & 78 & & \\
\hline \multicolumn{6}{|l|}{ Areal bone mineral density } \\
\hline Total body $\left(\mathrm{g} / \mathrm{cm}^{2}\right)^{\mathrm{a}}$ & $1.26 \pm 0.07$ & $1.27 \pm 0.09$ & $1.36 \pm 0.08 \mathbf{A}, \mathbf{B}$ & $<0.001$ & $<0.001$ \\
\hline Lumbar spine $\left(\mathrm{g} / \mathrm{cm}^{2}\right)^{\mathrm{a}}$ & $1.21 \pm 0.12$ & $1.23 \pm 0.14$ & $1.35 \pm 0.14 \mathbf{A}, \mathbf{B}$ & $<0.001$ & $<0.001$ \\
\hline Femoral neck $\left(\mathrm{g} / \mathrm{cm}^{2}\right)^{\mathrm{a}}$ & $1.06 \pm 0.13$ & $1.07 \pm 0.15$ & $1.26 \pm 0.17 \mathbf{A}, \mathbf{B}$ & $<0.001$ & $<0.001$ \\
\hline Total hip $\left(\mathrm{g} / \mathrm{cm}^{2}\right)^{\mathrm{a}}$ & $1.08 \pm 0.13$ & $1.09 \pm 0.16$ & $1.28 \pm 0.16 \mathbf{A}, \mathbf{B}$ & $<0.001$ & $<0.001$ \\
\hline Radius nondominant $\left(\mathrm{g} / \mathrm{cm}^{2}\right)$ & $0.62 \pm 0.05$ & $0.63 \pm 0.05$ & $0.63 \pm 0.04$ & 0.176 & 0.169 \\
\hline \multicolumn{6}{|l|}{ Tibial diaphysis } \\
\hline Cortical cross-sectional area $\left(\mathrm{mm}^{2}\right)$ & $267 \pm 26$ & $275 \pm 32$ & $309 \pm 28 \mathbf{A}, \mathbf{B}$ & $<0.001$ & $<0.001$ \\
\hline Cortical periosteal circumference (mm) & $73.2 \pm 3.3$ & $74.0 \pm 3.7$ & $76.5 \pm 3.3 \mathbf{A}, \mathbf{B}$ & $<0.001$ & $<0.001$ \\
\hline Cortical thickness (mm) & $4.54 \pm 0.46$ & $4.63 \pm 0.55$ & $5.12 \pm 0.55 \mathbf{A}, \mathbf{B}$ & $<0.001$ & $<0.001$ \\
\hline Cortical endosteal circumference (mm) & $44.6 \pm 4.4$ & $44.9 \pm 4.7$ & $44.4 \pm 4.9$ & 0.773 & 0.766 \\
\hline Cortical volumetric density $\left(\mathrm{mg} / \mathrm{cm}^{3}\right)$ & $1,168 \pm 16$ & $1,164 \pm 18$ & $1,156 \pm 20 \mathrm{~A}, \mathrm{~B}$ & $<0.001$ & $<0.001$ \\
\hline \multicolumn{6}{|l|}{ Radial diaphysis } \\
\hline Cortical cross-sectional area $\left(\mathrm{mm}^{2}\right)$ & $95.8 \pm 11.4$ & $98.9 \pm 11.1$ & $100.3 \pm 10.0 \mathrm{~A}$ & 0.005 & 0.007 \\
\hline Cortical periosteal circumference (mm) & $41.4 \pm 2.6$ & $42.2 \pm 2.6 \mathrm{a}$ & $42.6 \pm 2.5 \mathrm{~A}$ & 0.001 & 0.002 \\
\hline Cortical volumetric density $\left(\mathrm{mg} / \mathrm{cm}^{3}\right)$ & $1,194 \pm 16$ & $1,188 \pm 16 \mathrm{a}$ & $1,190 \pm 17$ & 0.008 & 0.006 \\
\hline \multicolumn{6}{|l|}{ Tibial metaphysis } \\
\hline Trabecular bone volume fraction $(\%)^{\mathrm{b}}$ & $17.6 \pm 2.5$ & $17.5 \pm 2.6$ & $20.2 \pm 2.4 \mathbf{A}, \mathbf{B}$ & $<0.001$ & $<0.001$ \\
\hline Trabecular number $\left(\mathrm{mm}^{-1}\right)^{\mathrm{b}}$ & $2.07 \pm 0.23$ & $2.04 \pm 0.26$ & $2.23 \pm 0.24 \mathbf{A}, \mathbf{B}$ & $<0.001$ & $<0.001$ \\
\hline Trabecular volumetric density $\left(\mathrm{mg} / \mathrm{cm}^{3}\right)^{\mathrm{b}}$ & $211.7 \pm 30.3$ & $210.6 \pm 31.7$ & $242.7 \pm 28.6 \mathbf{A}, \mathbf{B}$ & $<0.001$ & $<0.001$ \\
\hline Trabecular separation $(\mathrm{mm})^{\mathrm{b}}$ & $0.41 \pm 0.06$ & $0.41 \pm 0.06$ & $0.36 \pm 0.05 \mathbf{A}, \mathbf{B}$ & $<0.001$ & $<0.001$ \\
\hline Trabecular thickness $(\mu \mathrm{m})^{\mathrm{b}}$ & $85.8 \pm 10.5$ & $86.7 \pm 11.6$ & $91.2 \pm 9.6 \mathrm{~A}, \mathrm{~b}$ & 0.001 & 0.025 \\
\hline Cortical volumetric density $\left(\mathrm{mg} / \mathrm{cm}^{3}\right)^{\mathrm{b}}$ & $873 \pm 29$ & $867 \pm 30$ & $873 \pm 27$ & 0.243 & 0.182 \\
\hline \multicolumn{6}{|l|}{ Radial metaphysis } \\
\hline Trabecular bone volume fraction $(\%)^{\mathrm{c}}$ & $16.2 \pm 2.9$ & $16.5 \pm 2.8$ & $17.3 \pm 2.7 \mathrm{a}$ & 0.043 & 0.084 \\
\hline Trabecular number $\left(\mathrm{mm}^{-1}\right)^{\mathrm{c}}$ & $2.1 \pm 0.2$ & $2.1 \pm 0.2$ & $2.1 \pm 0.2$ & 0.679 & 0.673 \\
\hline Trabecular separation $(\mathrm{mm})^{\mathrm{c}}$ & $0.40 \pm 0.06$ & $0.41 \pm 0.06$ & $0.40 \pm 0.06$ & 0.674 & 0.620 \\
\hline Trabecular thickness $(\mu \mathrm{m})^{\mathrm{c}}$ & $77.3 \pm 12.4$ & $79.5 \pm 11.9$ & $82.4 \pm 12.4 \mathrm{a}$ & 0.016 & 0.057 \\
\hline Cortical volumetric density $\left(\mathrm{mg} / \mathrm{cm}^{3}\right)^{\mathrm{c}}$ & $850 \pm 41$ & $840 \pm 35$ & $851 \pm 35$ & 0.089 & 0.057 \\
\hline
\end{tabular}

Mean \pm SD of bone parameters, adjusted for height and weight, are presented. Differences between groups tested by ANCOVA followed by Tukey's post hoc test were performed $(n=361)$. $p$ values for vs. nonathletic (indicated by A) and vs. resistance training (indicated by B). Capital and capital bold type letters represent $p<0.01$ and $p<0.001$, respectively. Lowercase letters represent $p<0.05$

ANCOVA1 height and weight as covariates, ANCOVA2 smoking as a covariate

${ }^{\mathrm{a}} \mathrm{n}=359$

${ }^{\mathrm{b}} n=358$

${ }^{\mathrm{c}} n=317$

In the present study, the resistance training men did not differ in any bone parameter, in either weight-bearing or nonweight-bearing bone, compared to nonathletic men. In addition, we found no significant differences in daily transportation, sedentary behavior, or occupational physical load between the groups of men compared. Since this is a population-based study including subjects that represent the average population and not a selection of elite athletes, the results from the present study may be suitable to develop bone health recommendations for young adult men in general. Even if exercise by resistance training can offer several health benefits and increase muscle strength, our findings argue against recommending the increasingly popular exercise by resistance training to the younger population for the purpose of improving bone health. The majority of subjects in the resistance training group were exercising at a 
recreational level, while subjects in soccer-playing group were training at a competitive level. This may explain the higher lean mass (although this difference was not significant) among soccer players compared to the resistance training men.

There are some limitations of the present study. The crosssectional design does not allow for direct cause-effect relationships to be established. For this, it would be necessary to conduct a randomized controlled trial. It is possible that differences in bone variables may be due also to genetics and self-selection into sports. For example, individuals with genetically favorable musculature and skeleton may tend to be more successful in certain sports and, therefore, participate to a higher extent. However, we could not find any difference in body size parameters (height or weight) between subjects who had been active in sport activity and nonathletic subjects. Although this argues against a problem with selection bias, it cannot be ruled out that this is the cause of the associations found. A methodological limitation is that the bone structure parameters presented in this study have been obtained from 3D pQCT measurements and are thus density-based. This means, for example, that a trabecula or a cortex with higher bone density will be measured as having a greater thickness than a corresponding bone of the same actual thickness but with a lower density. Furthermore, the results from the present study derive from investigations of men aged 23-25 years and may not be applicable to other age groups. Present and former physical activity habits were assessed using a retrospective self-reporting questionnaire, which may have been subject to a limited ability of the subjects to recall their history of physical activity, and this effect may have caused bias and misclassification. However, by using a standardized self-administered questionnaire, based on a validated physical activity questionnaire [34], with amended questions concerning physical activity habits over the whole year, we believe that we have been able to collect accurate information about physical activity habits. Furthermore, some studies have reported that people can recall activity patterns from up to 10 years in the past with high reliability and that recall of more vigorous activity, such as sports and exercise, is more accurate than recall of less intensive activities [47, 48]. Since this study includes subjects who represent the average population and not a selection of elite athletes, the variety in different kinds of resistive exercise could not be controlled for. Furthermore, it is known that the change in bone density and geometry occurs at the region of the bone loaded [49]. Since we do not have information on the kinds of resistive exercises, loading levels, or number of sets and repetitions the subjects performed, we cannot exclude the possibility that resistive exercise may indeed have some impact on bone. Although the study had sufficient power to detect relatively small differences between the studied groups, we could not observe that aBMD, at either weight-bearing or nonweight-bearing bone sites, in the resistance training group differed as compared to aBMD in the nonathletic group.

In conclusion, the association between exercise loading and bone parameters is sport-specific. In concordance with previous studies, this study found that weight-bearing exercise, in this case soccer, with impacts from varying directions, is associated with changes in aBMD and vBMD, cortical bone geometry, and trabecular microstructure of weight-bearing bone. Nonspecific recreational resistance exercise does not appear to be a strong determinant of bone density, geometry, or microstructure in young adult men.

\section{Conflicts of interest None.}

Open Access This article is distributed under the terms of the Creative Commons Attribution Noncommercial License which permits any noncommercial use, distribution, and reproduction in any medium, provided the original author(s) and the source are credited.

\section{References}

1. Rizzoli R, Bonjour JP, Ferrari SL (2001) Osteoporosis, genetics and hormones. J Mol Endocrinol 26:79-94

2. Frost HM (1987) Bone "mass" and the "mechanostat": a proposal. Anat Rec 219:1-9

3. Nikander R, Sievänen H, Heinonen A, Daly RM, Uusi-Rasi K, Kannus P (2010) Targeted exercise against osteoporosis: a systematic review and meta-analysis for optimising bone strength throughout life. BMC Med 8:47

4. Heaney RP, Abrams S, Dawson-Hughes B, Looker A, Marcus R, Matkovic V, Weaver C (2000) Peak bone mass. Osteoporos Int 11:985-1009

5. Heinonen A, Oja P, Kannus P, Sievanen H, Haapasalo H, Manttari A, Vuori I (1995) Bone mineral density in female athletes representing sports with different loading characteristics of the skeleton. Bone 17:197-203

6. Heinonen A, Oja P, Kannus P, Sievanen H, Manttari A, Vuori I (1993) Bone mineral density of female athletes in different sports. Bone Miner 23:1-14

7. Taaffe DR, Snow-Harter C, Connolly DA, Robinson TL, Brown MD, Marcus R (1995) Differential effects of swimming versus weight-bearing activity on bone mineral status of eumenorrheic athletes. J Bone Miner Res 10:586-593

8. Taaffe DR, Robinson TL, Snow CM, Marcus R (1997) Highimpact exercise promotes bone gain in well-trained female athletes. J Bone Miner Res 12:255-260

9. Duncan CS, Blimkie CJ, Cowell CT, Burke ST, Briody JN, Howman-Giles R (2002) Bone mineral density in adolescent female athletes: relationship to exercise type and muscle strength. Med Sci Sports Exerc 34:286-294

10. Lanyon LE, Rubin CT (1984) Static vs. dynamic loads as an influence on bone remodelling. J Biomech 17:897-905

11. Turner CH (1998) Three rules for bone adaptation to mechanical stimuli. Bone 23:399-407

12. Kontulainen S, Sievanen H, Kannus P, Pasanen M, Vuori I (2002) Effect of long-term impact-loading on mass, size, and estimated strength of humerus and radius of female racquet-sports players: a peripheral quantitative computed tomography study between young and old starters and controls. J Bone Miner Res 17:2281-2289 
13. Lorentzon M, Mellstrom D, Ohlsson C (2005) Association of amount of physical activity with cortical bone size and trabecular volumetric BMD in young adult men: the GOOD study. J Bone Miner Res 20:1936-1943

14. Nilsson M, Ohlsson C, Mellstrom D, Lorentzon M (2009) Previous sport activity during childhood and adolescence is associated with increased cortical bone size in young adult men. J Bone Miner Res 24:125-133

15. Nikander R, Sievänen H, Uusi-Rasi K, Heinonen A, Kannus $P$ (2006) Loading modalities and bone structures at nonweightbearing upper extremity and weight-bearing lower extremity: a pQCT study of adult female athletes. Bone 39:886-894

16. Fehling PC, Alekel L, Clasey J, Rector A, Stillman RJ (1995) A comparison of bone mineral densities among female athletes in impact loading and active loading sports. Bone 17:205-210

17. Nikander R, Sievänen H, Heinonen A, Kannus P (2005) Femoral neck structure in adult female athletes subjected to different loading modalities. J Bone Miner Res 20:520-528

18. Nikander R, Kannus P, Dastidar P et al (2009) Targeted exercises against hip fragility. Osteoporos Int 20:1321-1328

19. Hui SL, Slemenda CW, Johnston CC Jr (1990) The contribution of bone loss to postmenopausal osteoporosis. Osteoporos Int 1:30-34

20. Kelly PJ, Morrison NA, Sambrook PN, Nguyen TV, Eisman JA (1995) Genetic influences on bone turnover, bone density and fracture. Eur J Endocrinol 133:265-271

21. Haapasalo H, Kontulainen S, Sievanen H, Kannus P, Jarvinen M, Vuori I (2000) Exercise-induced bone gain is due to enlargement in bone size without a change in volumetric bone density: a peripheral quantitative computed tomography study of the upper arms of male tennis players. Bone 27:351-357

22. Karlsson M (2002) Is exercise of value in the prevention of fragility fractures in men? Scand J Med Sci Sports 12:197-210

23. Proctor DN, Melton LJ, Khosla S, Crowson CS, O'Connor MK, Riggs BL (2000) Relative influence of physical activity, muscle mass and strength on bone density. Osteoporos Int 11:944-952

24. Khosla S, Atkinson EJ, Riggs BL, Melton LJ 3rd (1996) Relationship between body composition and bone mass in women. J Bone Miner Res 11:857-863

25. Faigenbaum AD, Kraemer WJ, Blimkie CJ, Jeffreys I, Micheli LJ, Nitka M, Rowland TW (2009) Youth resistance training: updated position statement paper from the National Strength and Conditioning Association. J Strength Cond Res 23:S60-S79

26. Haskell WL, Lee IM, Pate RR, Powell KE, Blair SN, Franklin BA, Macera CA, Heath GW, Thompson PD, Bauman A (2007) Physical activity and public health: updated recommendation for adults from the American College of Sports Medicine and the American Heart Association. Circulation 116:1081-1093

27. Martyn-St James M, Carroll S (2010) Effects of different impact exercise modalities on bone mineral density in premenopausal women: a meta-analysis. J Bone Miner Metab 28:251-267

28. Kohrt WM, Bloomfield SA, Little KD, Nelson ME, Yingling VR (2004) American College of Sports Medicine Position Stand: physical activity and bone health. Med Sci Sports Exerc 36:1985-1996

29. Nikander R, Kannus P, Rantalainen T, Uusi-Rasi K, Heinonen A, Sievanen H (2010) Cross-sectional geometry of weight-bearing tibia in female athletes subjected to different exercise loadings. Osteoporos Int 21:1687-1694

30. Faigenbaum AD, Myer GD (2010) Resistance training among young athletes: safety, efficacy and injury prevention effects. Br J Sports Med 44:56-63
31. Sievänen H (2000) A physical model for dual-energy X-ray absorptiometry-derived bone mineral density. Investig Radiol 35:325-330

32. Ohlsson C, Darelid A, Nilsson M, Melin J, Mellstrom D, Lorentzon M (2011) Cortical consolidation due to increased mineralization and endosteal contraction in young adult men: a five-year longitudinal study. J Clin Endocrinol Metab 96:2262-2269

33. Lorentzon M, Mellstrom D, Ohlsson C (2005) Age of attainment of peak bone mass is site-specific in Swedish men-the GOOD Study. J Bone Miner Res 20:1223-1227

34. Kemper HC, Bakker I, Twisk JW, van Mechelen W (2002) Validation of a physical activity questionnaire to measure the effect of mechanical strain on bone mass. Bone 30:799-804

35. MacNeil JA, Boyd SK (2007) Load distribution and the predictive power of morphological indices in the distal radius and tibia by high resolution peripheral quantitative computed tomography. Bone 41:129-137

36. Laib A, Hauselmann HJ, Ruegsegger P (1998) In vivo high resolution 3D-QCT of the human forearm. Technol Health Care 6:329-337

37. Nilsson M, Ohlsson C, Sundh D, Mellstrom D, Lorentzon M (2010) Association of physical activity with trabecular microstructure and cortical bone at distal tibia and radius in young adult men. J Clin Endocrinol Metab 95:2917-2926

38. Nilsson M, Ohlsson C, Oden A, Mellstrom D, Lorentzon M (2012) Increased physical activity is associated with enhanced development of peak bone mass in men: a five-year longitudinal study. $\mathrm{J}$ Bone Miner Res 27:1206-1214

39. Judex S, Carlson KJ (2009) Is bone's response to mechanical signals dominated by gravitational loading? Med Sci Sports Exerc 41:2037-2043

40. Nordstrom P, Nordstrom G, Thorsen K, Lorentzon R (1996) Local bone mineral density, muscle strength, and exercise in adolescent boys: a comparative study of two groups with different muscle strength and exercise levels. Calcif Tissue Int 58:402-408

41. Bass S, Pearce G, Bradney M, Hendrich E, Delmas PD, Harding A, Seeman E (1998) Exercise before puberty may confer residual benefits in bone density in adulthood: studies in active prepubertal and retired female gymnasts. J Bone Miner Res 13:500-507

42. Tobias JH, Steer CD, Mattocks CG, Riddoch C, Ness AR (2007) Habitual levels of physical activity influence bone mass in 11-yearold children from the United Kingdom: findings from a large population-based cohort. J Bone Miner Res 22:101-109

43. MacKelvie KJ, Khan KM, McKay HA (2002) Is there a critical period for bone response to weight-bearing exercise in children and adolescents? A systematic review. Br J Sports Med 36:250-257

44. Conroy BP, Kraemer WJ, Maresh CM, Fleck SJ, Stone MH, Fry AC, Miller PD, Dalsky GP (1993) Bone mineral density in elite junior Olympic weightlifters. Med Sci Sports Exerc 25:1103-1109

45. Karlsson MK, Johnell O, Obrant KJ (1993) Bone mineral density in weightlifters. Calcif Tissue Int 52:212-215

46. Tsuzuku S, Shimokata H, Ikegami Y, Yabe K, Wasnich RD (2001) Effects of high versus low-intensity resistance training on bone mineral density in young males. Calcif Tissue Int 68:342-347

47. Falkner KL, Trevisan M, McCann SE (1999) Reliability of recall of physical activity in the distant past. Am J Epidemiol 150:195-205

48. Slattery ML, Jacobs DR Jr (1995) Assessment of ability to recall physical activity of several years ago. Ann Epidemiol 5:292-296

49. Sugiyama T, Price JS, Lanyon LE (2010) Functional adaptation to mechanical loading in both cortical and cancellous bone is controlled locally and is confined to the loaded bones. Bone 46:314-321 